\title{
Constant Strain Rate Uniaxial Compression of Green Sandstone during SHPB Tests Driven by Pendulum Hammer
}

\author{
S. H. Li, W. C. Zhu, L. L. Niu, and F. Dai \\ Center for Rock Instability and Seismicity Research, Department of Mining Engineering, School of Resource and Civil Engineering, \\ Northeastern University, Shenyang 110819, China
}

Correspondence should be addressed to W. C. Zhu; zhuwancheng@mail.neu.edu.cn

Received 31 July 2017; Accepted 9 October 2017; Published 2 November 2017

Academic Editor: Longjun Dong

Copyright (C) 2017 S. H. Li et al. This is an open access article distributed under the Creative Commons Attribution License, which permits unrestricted use, distribution, and reproduction in any medium, provided the original work is properly cited.

\begin{abstract}
During the Split-Hopkinson pressure bar (SHPB) tests driven by pendulum hammer, employing a proper special shape striker is an effective way to obtain dynamic stress equilibrium condition and to get constant strain rate of the rock specimen. To find the proper special shape striker, a striker with a cambered surface was introduced and eight geometrically different hammers were designed to analyze the effect of hammer geometry on the waveform of excited incident stress waves. Based on experiments and simulations, parameter effects, including the cambered hammer curvature radius and hammer diameter, length, and impact velocity, on the incident wave shape were examined. These parametric studies provided guidelines for achieving constant strain rates in rock specimens during SHPB tests. The use of different diameter hammers was noted for shaping stress-time curves to follow the stress-strain behavior of green sandstone. Finally, to examine the applicability of using hammer geometry for shaping incident waves to achieve constant strain rate, SHPB tests on green sandstone specimens were conducted. The results demonstrated that a constant strain rate $\left(100 \mathrm{~s}^{-1}\right)$ lasting for $70 \mu \mathrm{s}$ was achieved with the $8 \#$ hammer $(3.7 \mathrm{~kg}$; curvature radius, diameter, and length of 100,70 , and $126.3 \mathrm{~mm}$, resp.). In addition, dynamic experiments on green sandstone were carried out under various strain rates and the results showed that the initial tangential modulus was almost unaffected by strain rate. The strain at peak stress tended to increase with rising strain rate and the dynamic strength of green sandstone showed an apparent rate dependency.
\end{abstract}

\section{Introduction}

In a variety of rock engineering and geophysical applications, such as earthquakes, mining, civil engineering, petroleum engineering, and physical geography, rock materials are in a dynamic loading state, where the strain rate is in the range of $10^{-4}$ to $10^{3}[1,2]$. The mechanical characteristics of rock materials show strong strain rate dependency and, therefore, it is very meaningful and important to accurately determine the dynamic constitutive relation of rock materials in a specific range of strain rate.

The Split-Hopkinson pressure bar (SHPB), originally developed by Kolsky, is a commonly used apparatus to obtain the dynamic properties of materials at high strain rates $[3,4]$. To accurately obtain dynamic constitutive relations of ratedependent rock from SHPB tests, dynamic stress equilibrium and constant strain rate conditions in samples are required [5]. However, in a common SHPB test, the incident pulse is a square waveform characterized by a short rising time, which is not ideal in rocks for approaching dynamic equilibrium and a constant strain rate. Usually, most results from SHPB tests are presented with an average strain rate, which is not proper for most rock materials, as they show strong strain rate effects [6]. A longer rising time in the incident wave pulse is an indispensable condition for achieving dynamic force equilibrium in rock samples before failure. Meanwhile, the incident wave pulse must mimic the stress-strain behavior of rock materials to achieve a constant strain-rate state.

In the past, many studies have been performed into strategies for shaping the incident pulse. Among them, there are two main methods, involving a pulse shaper and a specially shaped striker. To shape the incident pulse to guarantee a constant strain rate condition in a rock specimen, Ellwood et al. [7] have presented a preloading bar together with a dummy sample. Frantz et al. [8] have also placed a dummy sample directly on the impacting surface of the incident bar 
as a pulse shaper. However, these methods use an identical material as the pulse shaper and it is not suitable for brittle materials, such as rocks, ceramics, and cement. Reference [9] has reported that the loading stress wave is smoothed with a preloading bar material with lower strength than the main bar. Afterwards, in experiments on brittle materials, Frew et al. $[10,11]$ have placed a thin copper disk on the incident bar impact surface and analyzed the copper disk geometry effects on the incident pulses. In addition, Chen et al. [12] and Frew et al. [13] have proposed a copper-steel pulse shaper to obtain compressive stress-strain data for elastic-plastic materials. Furthermore, Vecchio and Jiang [14] have reported that, in SHPB tests conducted on high-work-hardening materials, high-strength, high-work-hardening rate (HSHWHR) materials are more conducive than soft materials for shaping an incident pulse for a constant strain rate. Xia et al. [15] have obtained constant strain rate conditions during dynamic loading by applying pulse shaper technique in Barre granite studies. In tests of low impedance specimens, such as POM and PP plastics, Lee et al. [16] have used a pulse shaper to increase the incident wave rise time. With a H62 pulse shaper, Li and $\mathrm{Xu}$ [17] have achieved an incident pulse with a shape similar to a triangular waveform. Naghdabadi et al. [18] have reported the effects of parameters such as pulse shaper thickness and diameter and striker bar length and velocity on the incident pulse shape. Chen et al. [19] have used a pulse shaper to filter out high frequency noise generated during impact and maintaining force equilibrium across a sample. Moreover, Heard et al. [20] have designed a novel annular pulse shaper, which produces stress equilibrium and constant strain rate in a chosen concrete test material. Chen et al. [21] have employed a pulse-shaping technique by sticking a pulse shaper on the impact end of the incident bar to prevent a sudden hit by the striker bar and ensure a nearly constant strain rate condition in a concrete specimen. Chen et al. [22] have showed that pulse-shaping effect with a small diameter copper shaper was best. Bagher Shemirani et al. [23] have studied the effects of parameters, such as striker bar velocity and diameter and pulse shaper thickness, on the incident wave and concluded that a small diameter and thick pulse shaper is proper for concrete tests. Song et al. [24] have stated that the thickness of a pulse shaper was proportional to the pulse wave rising time.

In addition to the aforementioned research on pulse shaper methods, specially shaped strikers have also been widely used to obtain a proper incident pulse for different materials. Initially, Christensen et al. [25] verified that conical striker bars shaped the input-stress to a ramp waveform. With a spindle-shaped ram, Li et al. [26] have produced a half-sine loading waveform, which is better in eliminating oscillation in tests and for providing better strain rate stability. To initiate a half-sine loading waveform that eliminates violent oscillation of the resulting dynamic stress-strain curve, Lok et al. [27] have proposed a tapered impact ram instead of the conventional uniform solid cylindrical bullet. By using two tapered striker bars at appropriate impact velocities, Lok and Zhao [28] have achieved approximately constant strain rate in dynamic tests of steel fiber-reinforced concrete. Notably, Li et al. [29-31] have presented a tapered striker to produce a half-sine waveform to ensure specimen deformation for dynamic stress equilibrium and constant strain rate conditions. Also, Lee and Park [32] have presented a pulseshaping technique for investigating the dynamic deformation behavior of bovine femur specimens. Baranowski et al. [33] have presented a parametric study of the Split-Hopkinson pressure bar to elaborate the striker's design variables, which influence the pulse peak shape produced by the incident bar. In experiments on cortical bone with viscoelastic properties, Bekker et al. [34] have presented a conically shaped striker. Moreover, Chen et al. [22] have reported that changing the striker dimensions, such as shape and length, and choosing a reasonable velocity produce better pulse-shaping effects.

Although there are many studies on pulse-shaping techniques, the proper dimensions of a pulse shaper and specially shaped striker for testing samples under conditions of dynamic equilibrium and constant strain rate are usually selected via trial and error $[14,18]$. Therefore, prior to testing, some general considerations should be addressed, based on the specimen's qualitative behavior, to properly select the pulse shaper and special shape striker dimensions, which can considerably reduce the trial and error process usually used for selecting the proper pulse shaper. Meanwhile, the stress-strain relationships under different constant strain rates have been rarely reported, although it is essential for the development of physically based, predictive, and constitutive material models [14].

In consideration of the poor repeatability of the pulse shaper method and the advantages of the specially shaped striker method, such as reusability and increased test repeatability $[6,34]$, the special shape striker method was selected as the first priority for further investigation. In this study, the goal was to produce constant strain rate incident waves by impacting the incident bar with a pendulum hammer with different geometric parameters at different impact velocities. To design the shape of this pendulum hammer, a onedimensional wave propagation program was used that was based on Hertz contacting theory and one-dimensional stress wave theory to simulate the input wave generated by a series of hammers with different geometric parameters. Moreover, the effects of geometric parameters, including curvature radius and hammer length, diameter, and impact velocity on the incident wave shape, were investigated based on experiments and simulations. From the obtained results, guidelines for achieving constant strain rate conditions were proposed. Finally, these guidelines were applied for producing constant strain rate conditions in green sandstone and the effects of strain rate on the stress-strain curves of green sandstone under dynamic loading were presented.

\section{Experimental Setup and Theoretical Formulations}

2.1. Qualitative Stress-Strain Relationship of Green Sandstone. The green sandstone specimens were obtained from a mine in Neijiang, China. The composition of green sandstone is $60 \%$ quartz, $20 \%$ feldspar, $15 \%$ cement, and $5 \%$ mica. The grain size of the green sandstone varies from 200 to $500 \mu \mathrm{m}$. The physical-mechanical parameters of green sandstone samples 
TABLE 1: Physical-mechanical parameters of green sandstone samples.

\begin{tabular}{lccccc}
\hline $\begin{array}{l}\text { Density } \\
\left(\mathrm{g} \cdot \mathrm{cm}^{-3}\right)\end{array}$ & $\begin{array}{c}\text { Wave velocity } \\
\left(\mathrm{km} \cdot \mathrm{s}^{-1}\right)\end{array}$ & $\begin{array}{c}\text { Elastic Modulus } \\
(\mathrm{GPa})\end{array}$ & $\begin{array}{c}\text { Uniaxial compressive } \\
\text { strength }(\mathrm{MPa})\end{array}$ & $\begin{array}{c}\text { Tensile strength } \\
(\mathrm{MPa})\end{array}$ & $\begin{array}{c}\text { Poisson's } \\
\text { ratio }\end{array}$ \\
\hline 2168.4 & 2.63 & 8.4 & 30.1 & 2.27 & 0.29 \\
\hline
\end{tabular}

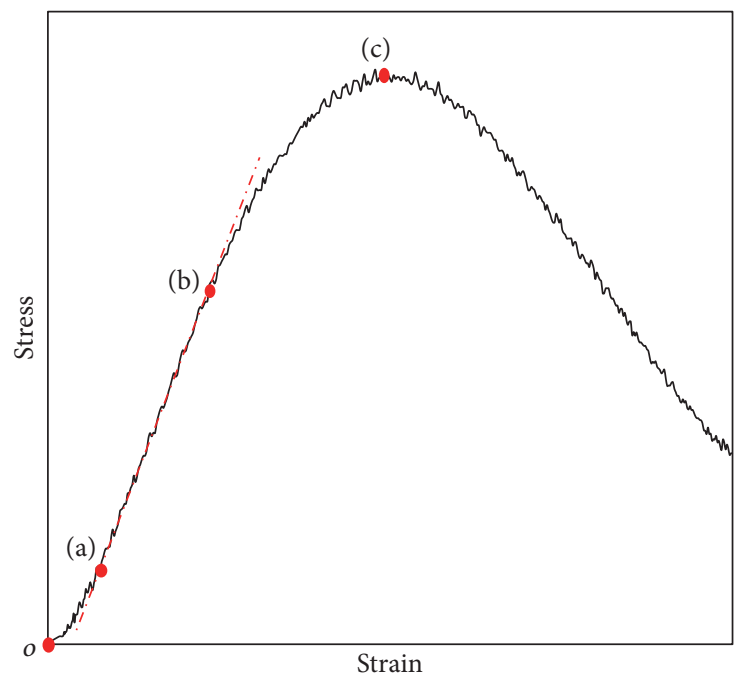

FIGURE 1: Qualitative stress-strain relationship of green sandstone.

are shown in Table 1. In the SHPB tests, rock specimens were prepared according to previously suggested test methods of the International Society for Rock Mechanics [36]. The diameter and thickness of green sandstone specimens were 28 and $15 \mathrm{~mm}$, respectively. The ends of the specimen are flat to $0.02 \mathrm{~mm}$ and parallel to within $0.25^{\circ}$.

From a qualitative aspect, the stress-strain curve of green sandstone was nearly a straight line in the lower stress range (Figure 1, (a)(b)), and after stress exceeds the elastic limit (Figure 1, (b)(c)), the stress increases with a decreasing rate. That is to say, the slope of the curve becomes lower with increasing stress.

In a conventional SHPB test, the specimen is sandwiched between the incident and transmission bars (Figure 2). As an incident wave $\left(\varepsilon_{I}(t)\right)$ propagates in the pressure bar, a tensile wave $\left(\varepsilon_{R}(t)\right)$ is reflected into the incident bar and a compressive wave $\left(\varepsilon_{T}(t)\right)$ transmitted into the transmission bar because the impedance of the rock specimen is smaller than the impedance of the pressure bars [3].

Assuming dynamic stress equilibrium in the rock sample is achieved, we obtain [18]

$$
E_{0} A_{0} \varepsilon_{I}(t)-A_{s} \sigma_{s}(t)=\frac{H_{s} A_{0} E_{0}}{2 C_{0}} \dot{\varepsilon}_{s}(t)
$$

where $C_{0}$ is the $\mathrm{P}$ wave velocity propagating in the pressure bars, $H_{s}$ and $A_{s}$ are the length and the cross-sectional area of the rock specimen, respectively, $A_{0}$ and $E_{0}$ are the cross-sectional area and Young's modulus of the elastic bars, respectively, and $\dot{\varepsilon}_{s}(t)$ and $\sigma_{s}(t)$ are the strain rate and stress of the rock specimen, respectively.

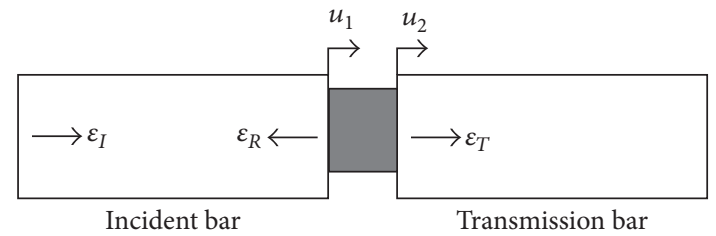

FIgURE 2: Schematic of wave propagation in Split-Hopkinson pressure bars.

From (1), the constant strain rate condition needs the incident pulse, which is proportional to the rock sample stress. Therefore, in a SHPB experiment, it was crucial to find an incident wave with a shape similar to the curve of the stress-strain of green sandstone.

2.2. Pendulum Hammer-Driven SHPB Apparatus. A Pendulum hammer-driven SHPB apparatus was selected for the SHPB tests (Figure 3). During SHPB tests, the incident bar was impacted by the cambered surface hammer, which generated a ramp incident wave with a long wave rising time. Introducing a cambered surface as the impact site was expected to result in a gradual building up of the incident wave thus increased the wave rise duration, which is essential for SHPB testing of rock materials.

By using a striker with a particular shape (Figure 4), it was possible to produce an appropriate incident stress wave that was similar to the stress-strain curve of green sandstone (Figure 5). In this respect, a constant strain rate in a rock specimen can be achieved during SHPB tests. To further study features of the incident wave, the rising portion of the incident wave was divided into three segments: initial segment $\left(t_{1}\right)$, linear segment $\left(t_{2}\right)$, and curved segment with a decreasing slope trend $\left(t_{3}\right)$. The initial segment is just a small part of the wave rise and, because rock samples did not fail in this initial loading phase, it was not discussed in this study.

The shape and duration of the incident wave depend on the geometry of the hammer and its impact velocity. This study presents a comprehensive parametric study of geometric parameters, including the curvature radius of the cambered surface $(R)$, hammer length $(L)$ and diameter $(D)$, and the impact velocity $(V)$, to clarify the factors affecting incident wave shape generated by pendulum hammer impact.

The rising portion of the incident wave was of greatest importance for achieving dynamic stress equilibrium and ensuring constant strain rate conditions in the rock specimen. As attaining stress equilibrium in the specimen is a prerequisite for valid SHPB tests, the time duration of the rising portion has to be long enough such that the stress wave travels in the specimen for more than 3-4 rounds [5]. Unlike a conventional rectangular incident wave, the rising pulse shape should be shaped to mimic the constitutive 


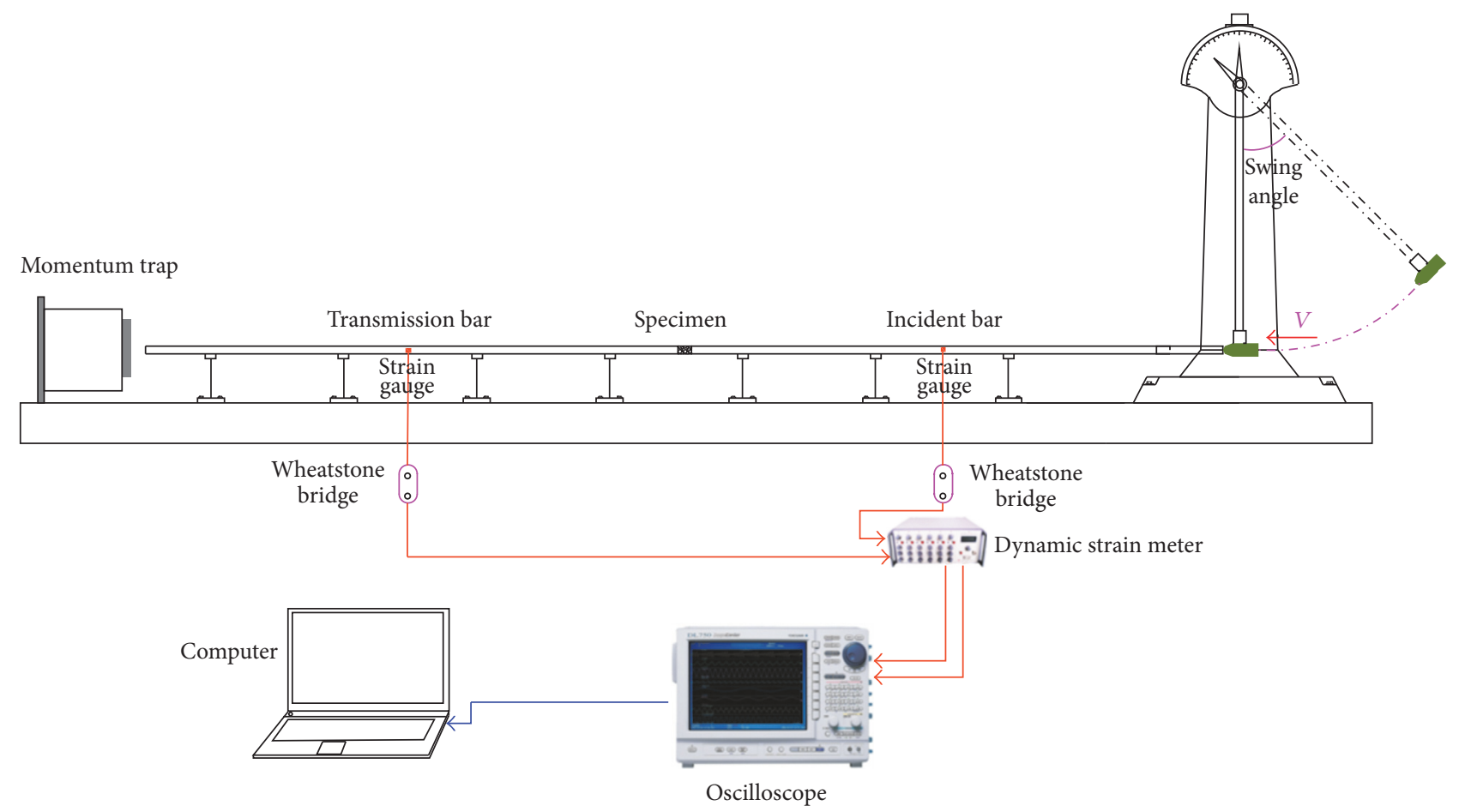

FIgURE 3: Pendulum hammer-driven SHPB apparatus [35].

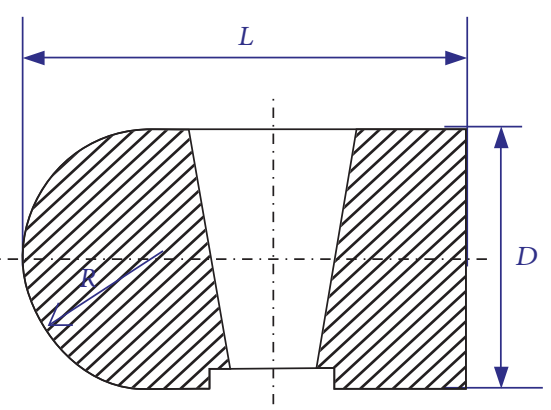

FIGURE 4: Appearance of pendulum hammer with cambered surface.

behavior of the green sandstone specimen [18]. Therefore, to accurately achieve a constant strain rate, the incident wave should be shaped to have a nearly linear segment in the lower stress range and a curved segment in the higher stress range to mimic the stress-strain behavior of green sandstone [6]. According to the discussion above, it was crucial to study how to simply and effectively alter the rising portion of the wave to mimic the constitutive behavior of a green sandstone specimen, which is a requirement for a constant strain rate.

2.3. The Nonlinear Theory Model of the Impact. Based on Hertz contacting theory, [37] presented a nonlinear theory model of the partial deformation on longitudinally impacted surface of bars to theoretically analyze the impact process between hammer and drill rod, as shown in Figure 6. Zou built on the nonlinear theory model of the impact and presented the one-dimensional wave propagation program,

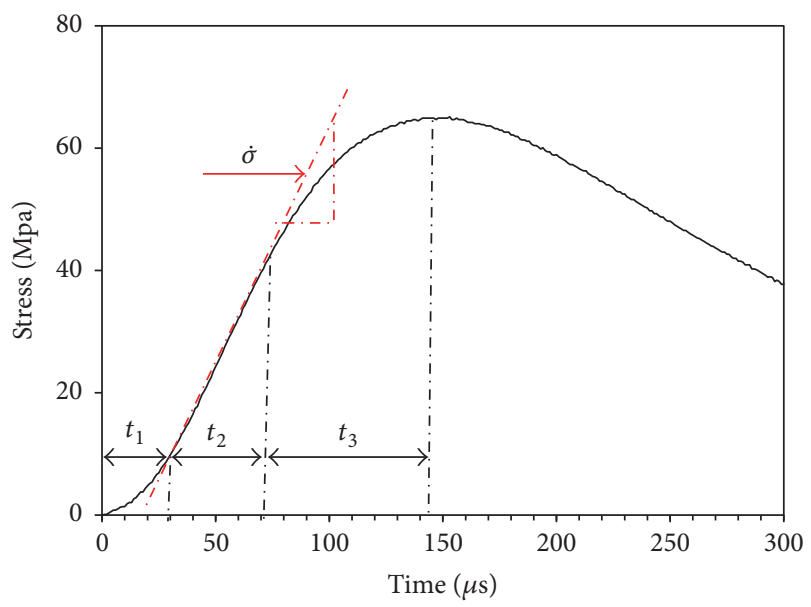

FIGURE 5: Appearance of incident wave.

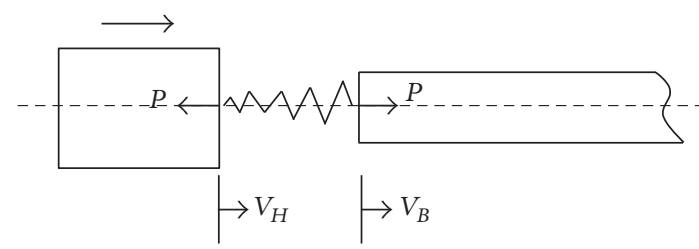

FIGURE 6: The nonlinear theoretical model of the impact.

a combination of the nonlinear theory model and onedimensional stress wave theory, which is proved to be able to get the simulated wave similar to the ones from experiments. 
The characteristic of the impact surface local deformation is simulated by a massless nonlinear spring. The mechanics equations in the processing of impacting are given by

$$
P^{2 / 3}=h_{1}\left(u_{H}-u_{B}\right),
$$

where $u_{H}$ and $u_{B}$ are the displacements in the hammer and incident bar, $P$ is the pressure on the impact surface, $V_{H}$ and $V_{B}$ are the particle velocities in the hammer and incident bar, and $h_{1}$, the most important parameter, is the "characteristic parameter" of the impact surface, which is given by

$$
\begin{aligned}
& h_{1}=\left(\frac{16}{9 \pi^{2}} \frac{R_{1} R_{2}}{\left(k_{1}+k_{2}\right)^{2}\left(R_{1}+R_{2}\right)}\right)^{1 / 3} \\
& k_{1}=\frac{1-v_{1}^{2}}{\pi E_{1}}, k_{2}=\frac{1-v_{2}^{2}}{\pi E_{2}},
\end{aligned}
$$

where $R_{1}, R_{2}$ are the radiuses of curvature of contact surfaces of the hammer and incident bar, $v_{1}, v_{2}$ are Poisson's ratios of the impactors, and $E_{1}, E_{2}$ are the Elastic Moduli of the impactors.

By taking the derivatives of (2), we obtain

$$
\frac{2}{3} P^{-1 / 3} \frac{d P}{d t}=h_{1}\left(V_{H}-V_{B}\right)
$$

We get the fundamental equations by combining (4) and the equations of stress wave propagation, which can be expressed as

$$
\begin{aligned}
\frac{2}{3} P^{-1 / 3} \frac{d P}{d t} & =h_{1}\left(V_{H}-V_{B}\right) \\
P & =p_{H}+q_{H}=p_{B}+q_{B} \\
V_{H} & =v_{H}+v_{H}^{\prime} ; \\
V_{B} & =v_{B}+v_{B}^{\prime} \\
p_{H} & =m_{H} v_{H} ; \\
q_{H} & =-m_{H} v_{H}^{\prime} \\
p_{B} & =m_{B} v_{B} ; \\
q_{B} & =-m_{B} v_{B}^{\prime},
\end{aligned}
$$

where $V_{H}$ and $V_{B}$ are the velocity in the hammer and incident bar; $p_{H}$ and $q_{H}$ are pressure of advancing downstream wave in the hammer and incident bar; $q_{H}$ and $q_{B}$ are pressure of retreating upstream wave in the hammer and incident bar; $v_{H}$ and $v_{B}$ are the particle velocity of advancing downstream wave in the hammer and incident bar; $v_{H}^{\prime}$ and $v_{B}^{\prime}$ are the particle velocity of retreating upstream wave in the hammer and incident bar; $m_{H}$ and $m_{B}$ are wave impedance of the hammer and incident bar.

In the pendulum hammer-driven SHPB apparatus, a hammer with a cambered surface as the impact end instead of the conventional cylinder is used to impact the incident bar, which is in accord with the contact theory of two elastomers presented by Hertz. So, the one-dimensional wave propagation program, which is based on the nonlinear impact model and the one-dimensional stress wave, is used to simulate the stress wave created by the pendulum hammerdriven SHPB apparatus.

\section{The Parameter Analysis}

The dynamic behavior of green sandstone was studied by examining the influence of geometric parameters and impact velocity of the pendulum hammer on the shape of the incident wave.

According to Hertz contacting theory, Zou et al. [37] have presented a nonlinear theory model of partial deformation on longitudinally impacted surfaces of bars to theoretically analyze the hammer impact process and, based on the principle of one-dimensional wave propagation, a one-dimensional stress wave program has been developed [35] to simulate wave propagation in rock specimens and bars during SHPB tests driven by a pendulum hammer (Figure 3 ).

According to the theory of stress wave propagation, the stress wave, created by the pendulum hammer, is affected by many factors, generally including geometrical shape, material parameters, and impact velocity. Number 45 steel, with a quenching hardness of HRC45, was selected as the hammer material. In the case of a certain metal, the hammer weight is determined by the volume and the volume determined by its geometric parameters, that is, the curvature radius of the hammer's cambered face and hammer diameter and length.

The effects of curvature radius and hammer diameter and length on the shape of incident waves generated by the hammer were studied using a series of hammers. As hammer geometry needed to be controlled within a reasonable range for ease of use, the hammer weight was chosen to be $<5 \mathrm{~kg}$ and hammer length $<300 \mathrm{~mm}$. Three diameters (56, 70, and $80 \mathrm{~mm}$ ) and three curvature radiuses $(40,100$, and $160 \mathrm{~mm}$ ) were selected to produce eight hammers (Table 2).

\subsection{Linear Wave Segment}

3.1.1. Effects of Geometric Parameters on Linear Wave Segments. The linear segment of an incident wave generated by hammers with different geometries and the same impact velocity $(2.5 \mathrm{~m} / \mathrm{s})$ showed that the experimental results were in good agreement with simulation results (Figure 7). The loading rate (slope) of linear segments showed strong dependence on curvature radius. Increasing the radius resulted in significant increases in the loading rate of linear segments. In contrast, with the same radius, changes in weight, diameter, and length showed little influence on the loading rate of linear segments. Moreover, the data showed that the duration of linear segments decreased slightly with the radius.

3.1.2. Effects of Impact Velocity on Linear Wave Segments. The results from experiments and numerical simulations for the linear wave segments generated by the $7 \#$ hammer with different impact velocities showed that, despite some differences in the values, the results were in good agreement (Figure 8). Increased impact velocity was concluded to have 
TABLE 2: Hammer geometric parameters.

\begin{tabular}{lcccc}
\hline Number $(\#)$ & Weight $(\mathrm{kg})$ & Diameter $(\mathrm{mm})$ & Curvature radius $(\mathrm{mm})$ & Length $(\mathrm{mm})$ \\
\hline$(1)$ & 4.9 & 56 & 40 & 100 \\
271.4 \\
$(2)$ & 4.9 & 56 & 160 & 268 \\
$(3)$ & 4.9 & 56 & 40 & 267.2 \\
$(4)$ & 4.9 & 80 & 100 & 135.9 \\
$(5)$ & 4.9 & 80 & 160 & 126.7 \\
$(6)$ & 4.9 & 80 & 100 & 125.1 \\
$(7)$ & 2.4 & 56 & 100 & 124 \\
$(8)$ & 3.7 & 70 & & 126.3 \\
\hline
\end{tabular}

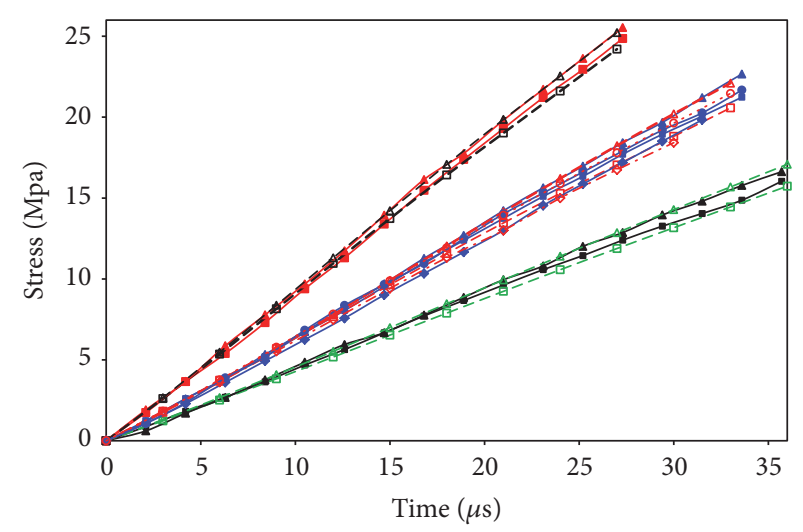

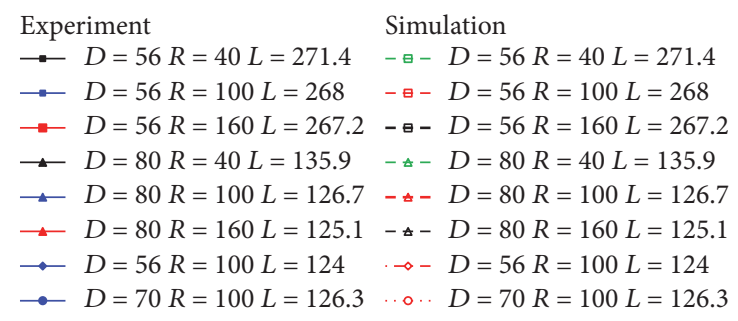

FIGURE 7: Hammer geometric parameter effects on linear segments of incident waves.

great influence on the loading rates of linear segments. Therefore, a high impact velocity led to a large loading rate.

3.1.3. Quantitative Relationship of between the Loading Rate and Curvature Radius. The results from comparison of the loading rate of incident waves versus hammer curvature radius under different impact velocities showed that the relationship between loading rate $(\dot{\sigma})$ and curvature radius $(R)$ under different impact velocities was expressed as follows (Figure 9):

$$
\begin{aligned}
& \text { Impact velocity }=2.0 \mathrm{~m} / \mathrm{s}: \dot{\sigma}=0.0025 R+0.1797 \\
& \text { Impact velocity }=2.5 \mathrm{~m} / \mathrm{s}: \dot{\sigma}=0.0039 R+0.2791 \\
& \text { Impact velocity }=3.0 \mathrm{~m} / \mathrm{s}: \dot{\sigma}=0.0052 R+0.3704 \\
& \text { Impact velocity }=3.5 \mathrm{~m} / \mathrm{s}: \dot{\sigma}=0.0061 R+0.438 \\
& \text { Impact velocity }=4.0 \mathrm{~m} / \mathrm{s}: \dot{\sigma}=0.0072 R+0.5186
\end{aligned}
$$

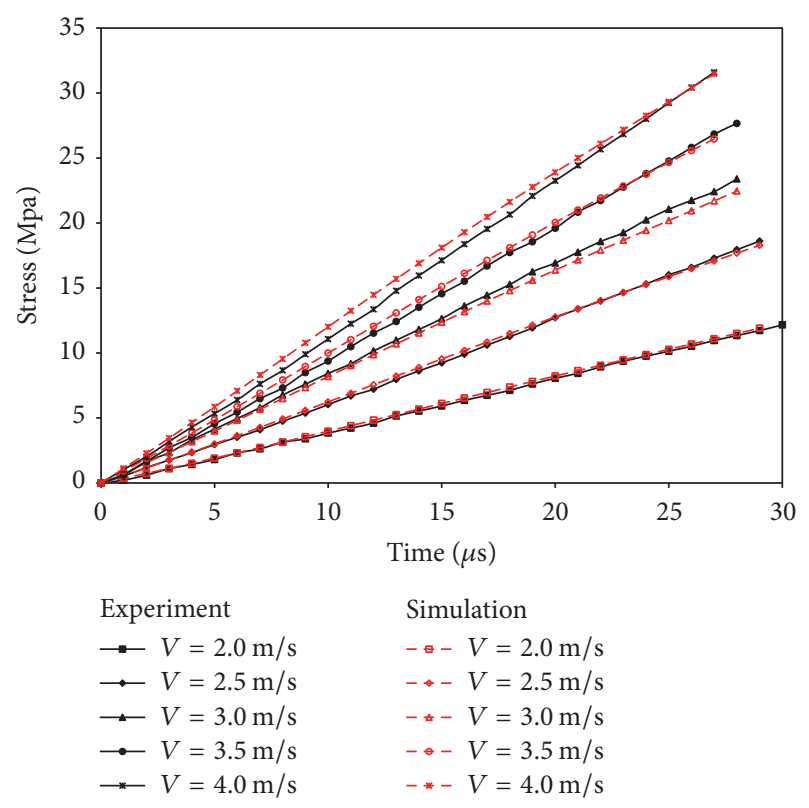

FIGURE 8: Impact velocity effects on linear segments of incident waves.

Using these equations, selection a hammer curvature radius under different impact velocities was easier for achieving a specific loading rate of the incident wave.

\subsection{Curved Wave Segment}

3.2.1. Effects of Geometric Parameters on Curved Wave Segments. The effects of hammer geometric parameters on the shape of curved wave segments generated by hammers with a $2.5 \mathrm{~m} / \mathrm{s}$ impact velocity showed that the experimental results and simulations were in a good agreement (Figure 10). Clearly, increasing of the curvature radius led to a higher loading rate in the curved segment. By comparing $3 \#$ and $6 \#$ hammer (Table 1), which had the same weight and radius, the shapes of the curved segments were affected by hammer shape. These results exhibited slight differences in the curved segment duration, although the duration and peak values of the curved segments generated by $3 \#$ hammer were longer than those of $6 \#$ hammer. Comparing the results from $2 \#$ and $7 \#$ hammers, the shapes of the curved segments were concluded to be affected by hammer length. Moreover, the 


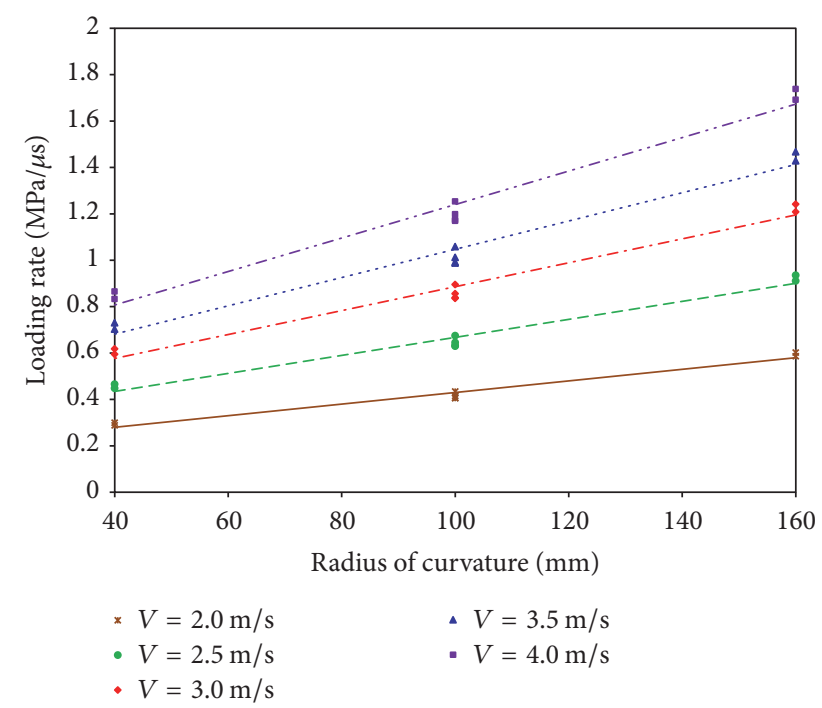

Figure 9: The relationship between loading rate and curvature radius under different impact velocities.

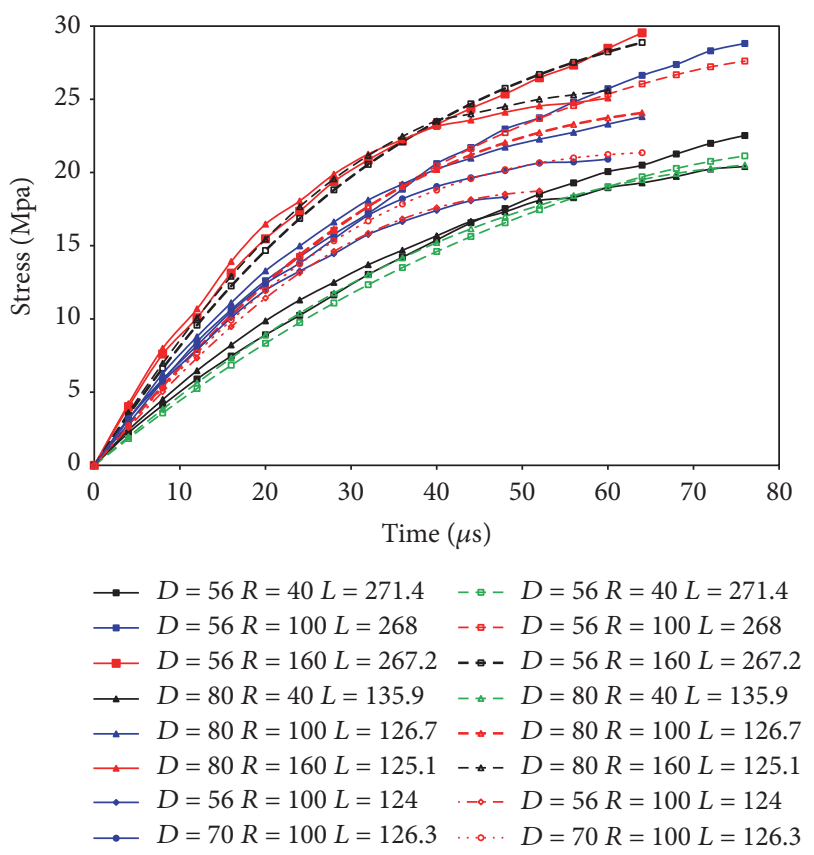

Figure 10: Hammer geometric parameter effects on the curved segment of incident waves.

duration of the curved segments showed an increasing trend with length. Meanwhile, the curved segment loading rate increased with increased length. Comparing the results of $5 \#$, $7 \#$, and $8 \#$ hammers, the shapes of the curved segments were concluded to be affected by hammer diameter. The duration of the curved segments as well as the loading rates of the segments increased with increased diameter.

The effects of hammer diameter and length on the curved segment shape were further investigated using simulations (Figures 11 and 12).

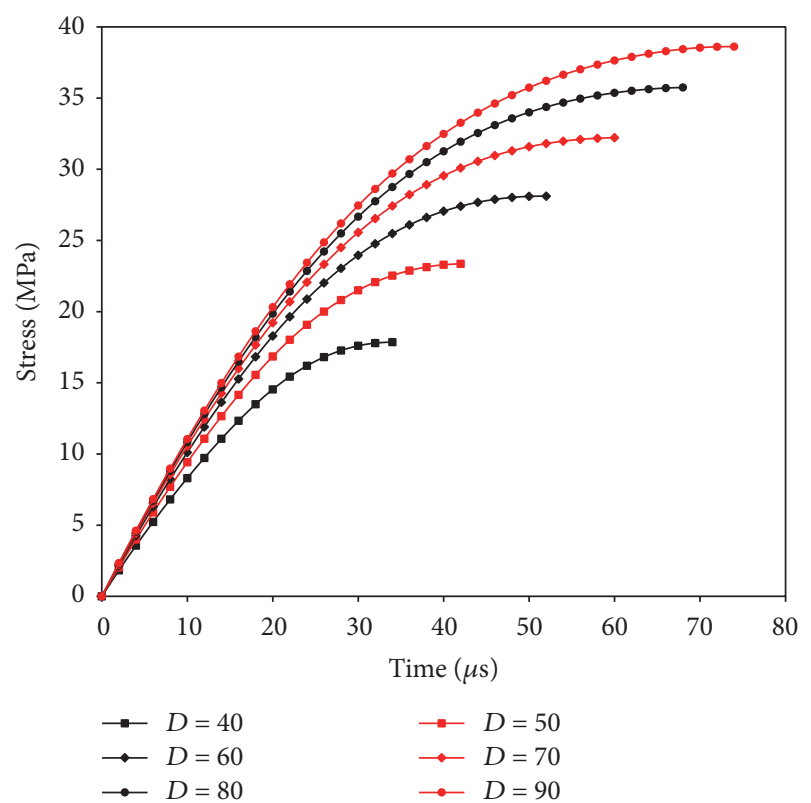

FIGURE 11: Hammer diameter effects on the curved segment of incident waves.

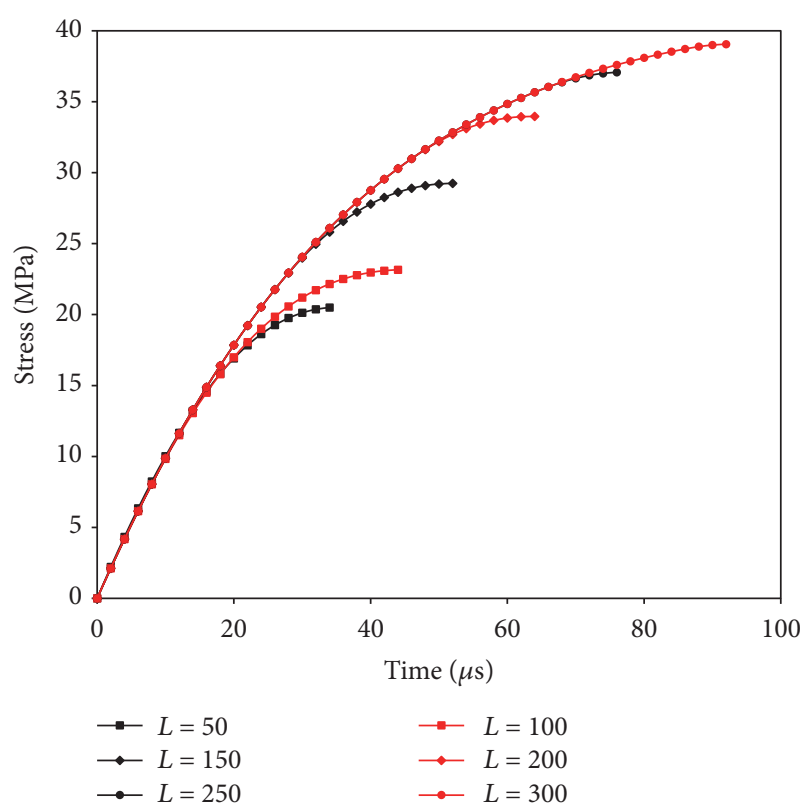

FIGURE 12: Hammer length effects on curved segments of incident waves.

The effects of hammer diameter on the shape of curved wave segments, with hammer length, curvature radius, and impact velocity at $125 \mathrm{~mm}, 100 \mathrm{~mm}$, and $2.5 \mathrm{~m} / \mathrm{s}$, respectively, showed that the duration and stress peak of curved segments increased with increased diameter (Figure 11). Moreover, the curved segments showed little overlap and the slope of the curved segment increased with increased hammer diameter. Interestingly, this relationship conveniently produced a series of incident waves with different curved segments by adjusting the hammer diameter while keeping the hammer length, curvature radius, and impact velocity constant. 
The effects of hammer length on the shape of the curved segments showed that, with hammer diameter, curvature radius, and impact velocity at $56 \mathrm{~mm}, 100 \mathrm{~mm}$, and $2.5 \mathrm{~m} / \mathrm{s}$, respectively, the duration and stress peak of the curved segments increased with increased hammer length (Figure 12). Unlike the results from hammers with different diameters, the majority of the incident wave curves generated by smaller hammer length overlapped with the curves generated by longer lengths, such that the curves did not show clear differences with increasing hammer length.

By comparing the above results, adjusting hammer diameter was concluded to be more efficient than adjusting hammer length for producing abundant and adjustable curved wave segments.

3.2.2. Effects of Impact Velocity on the Curved Wave Segments. Comparison of curved wave segment results generated by 7\# hammer with different impact velocities showed that the experimental and simulation results were in good agreement (Figure 13). Clearly, the loading rates of the curved segments increased significantly with increased impact velocity. Also, with increased impact velocity, the duration of the curved segments decreased and the stress peak increased.

3.3. Guidelines for Achieving Constant Strain Rates. From the above results, the parameters affecting the shape of the incident wave, that is, hammer diameter and length, curvature radius of the cambered surface, and impact velocity, were experimentally and numerically examined.

In this study, the purpose was to determine the quantitative behavior of green sandstone under a desired constant strain rate level. By determining the proper dimensions and impact velocity of the hammer, the incident wave can be shaped to achieve a constant strain rate condition and dynamic stress equilibrium in a rock specimen. In SHPB tests, to achieve a constant strain rate condition, the linear segment should be held invariable to ensure the same loading history, and then the curved portion can be adjusted to mimic the constitutive behavior of the green sandstone specimen.

Guidelines for achieving a constant strain rate condition under different strain rates are presented here:

(1) The desired loading rate of the incident stress wave can be obtained mainly by changing the hammer impact velocity or curvature radius of the hammer's cambered surface.

(2) The constant rate condition in the green sandstone specimen under a desired strain rate can be fulfilled primarily by adjusting the hammer diameter while keeping the hammer curvature radius, length, and impact velocity constant.

\section{Application to SHPB Tests}

4.1. SHPB Test for Green Sandstone. The incident stress waves were generated by hammers of $2 \#, 5 \#$, and $8 \#$ under the velocity of $3.0 \mathrm{~m} / \mathrm{s}$ (Figure 14). The three hammers were with the same curvature radius and almost same length. Meanwhile, their diameters were 50,70 , and $80 \mathrm{~mm}$. The linear wave segments of the three incident stress waves are the same, while the curved wave segments of the three incident stress waves are with different shapes.

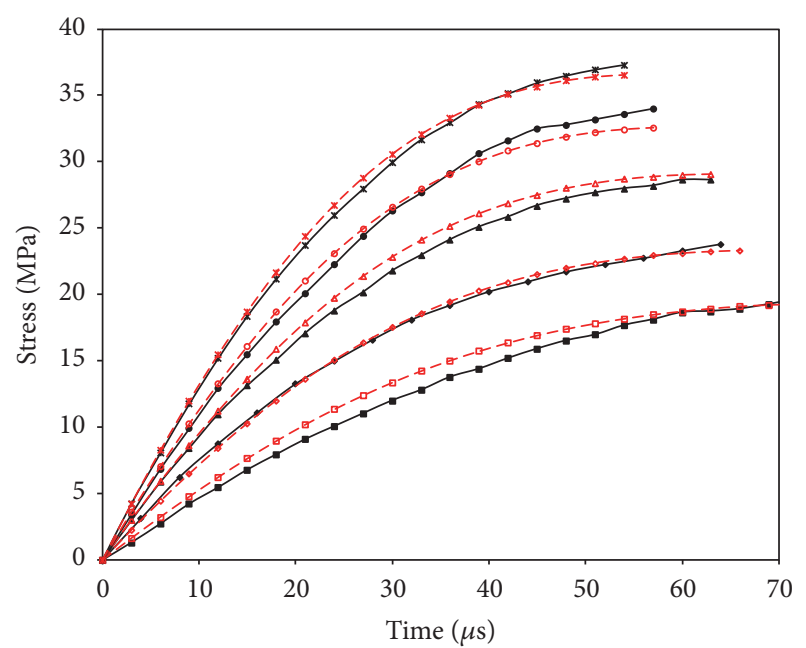

$$
\begin{array}{ll}
\text { Experiment } & \text { Simulation } \\
\because V=2.0 \mathrm{~m} / \mathrm{s} & --V=2.0 \mathrm{~m} / \mathrm{s} \\
\multimap V=2.5 \mathrm{~m} / \mathrm{s} & --V=2.5 \mathrm{~m} / \mathrm{s} \\
\multimap V=3.0 \mathrm{~m} / \mathrm{s} & --V=3.0 \mathrm{~m} / \mathrm{s} \\
\multimap V=3.5 \mathrm{~m} / \mathrm{s} & --V=3.5 \mathrm{~m} / \mathrm{s} \\
\multimap V=4.0 \mathrm{~m} / \mathrm{s} & -* V=4.0 \mathrm{~m} / \mathrm{s}
\end{array}
$$

FIGURE 13: Effects of impact velocity on curved segments of incident waves.

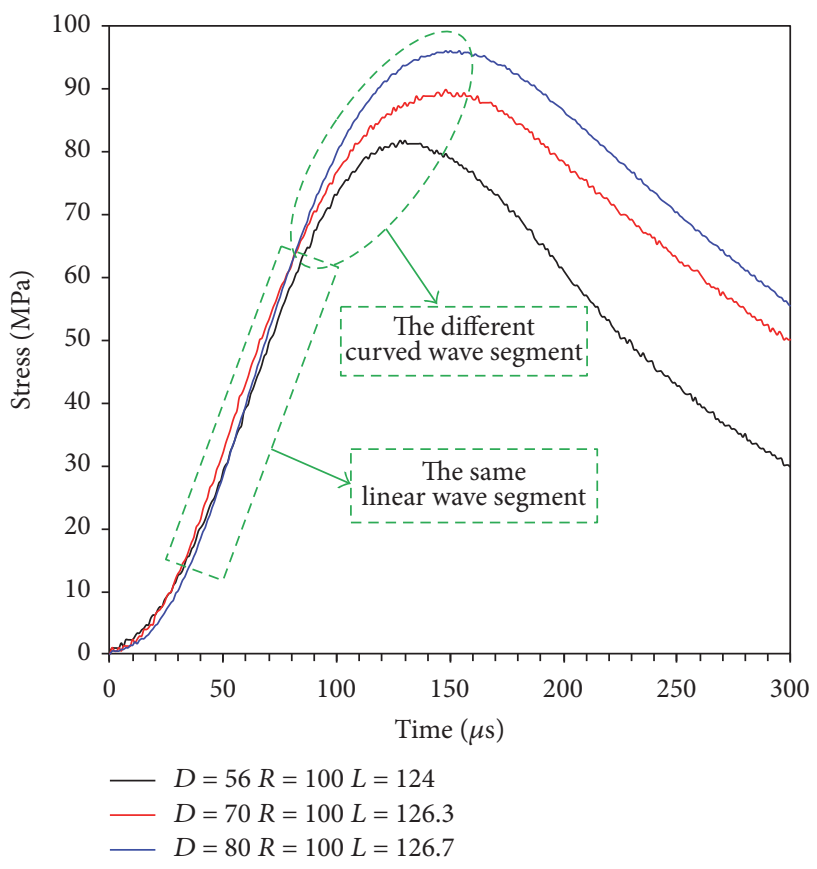

FIGURE 14: Incident waves generated in SHPB tests.

Due to the long duration of the linear segment of three incident waves, dynamic stress equilibrium was achieved theoretically. For simplification, only the stress condition in a specimen with 8 \# hammer as the striker bar was considered here. The dynamic stress in the green sandstone specimen dynamic compression test showed that the value of the transmitted wave equaled the incident wave plus the reflected 


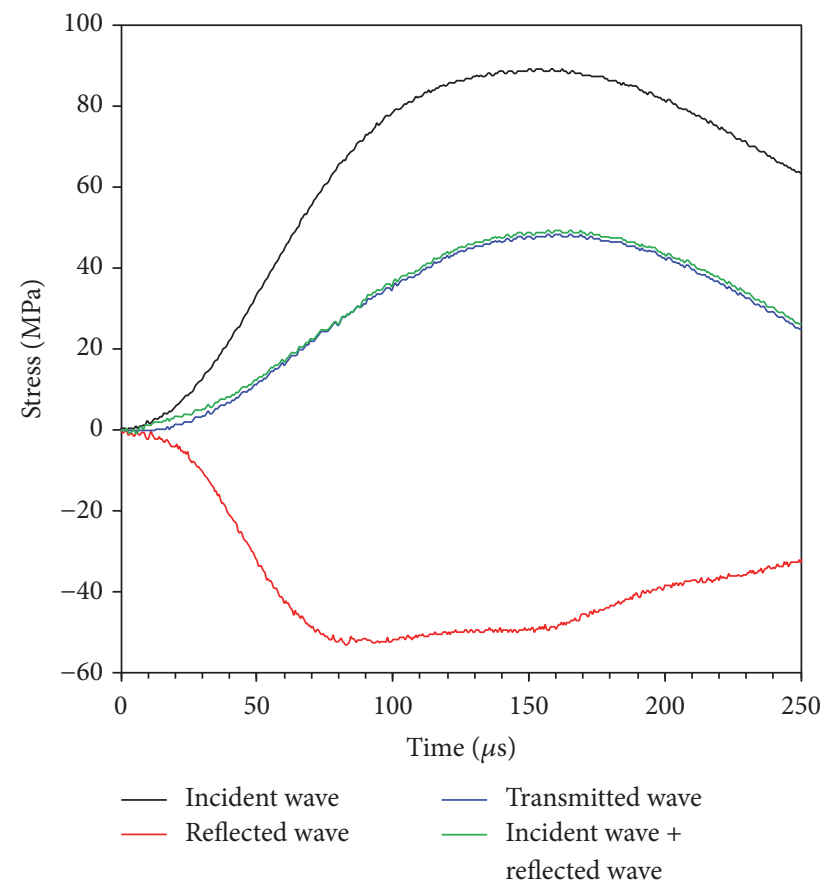

FIGURE 15: Dynamic stresses on both ends of a rock specimen.

wave nearly exactly after the stress waved had traveled in the rock sample for $\sim 5$ rounds ( $30 \mu$ s, Figure 15). With long duration of the rising part, dynamic stress equilibrium in the rock specimen was easily achieved. That is to say, the axial inertial effect was considered to be negligible as there was no stress gradient in the rock specimen.

Comparing the incident waves and the strain rate variations from SHPB tests with different hammers in three experiments revealed that the strain rates were very close over the time span from 0 to $90 \mu$ s because the incident wave is very close at the same time span (Figure 16), while the strain rate showed gaps between the three experiments from 90 to $160 \mu$ s because the incident waves diverged in this time span. The method for achieving a constant strain rate condition of the rock specimen involved adjusting the incident wave according to the strain rate during the rock's deformation. In results using $5 \#$ hammer, the strain rate continued to increase to a peak value at $110 \mu$ s and then decreased with time. In results from $7 \#$ hammer, the strain rate continued to increase to a peak value at $100 \mu$ s and then also decreased with time. Notably, the strain rate values from $5 \#$ hammer were higher than those of 7\# hammer from 90 to $160 \mu$ s. Thus, an incident wave with a loading rate between those of $5 \#$ and $7 \#$ hammer was needed for achieving a constant strain rate condition of a rock specimen from 90 to $160 \mu \mathrm{s}$. According to the guidelines presented above, to achieve a constant strain rate, a hammer with a diameter between 56 and $80 \mathrm{~mm}$ was needed. Thus, $8 \#$ hammer with the diameter of $70 \mathrm{~mm}$ was selected and a constant strain rate of $100 \mathrm{~s}^{-1}$ which lasted for $70 \mu \mathrm{s}$ in a green sandstone specimen was produced. The trial and error process for selecting the proper hammer to achieve a constant strain rate was considerably reduced by knowing to adjust the hammer diameter, per the guidelines.

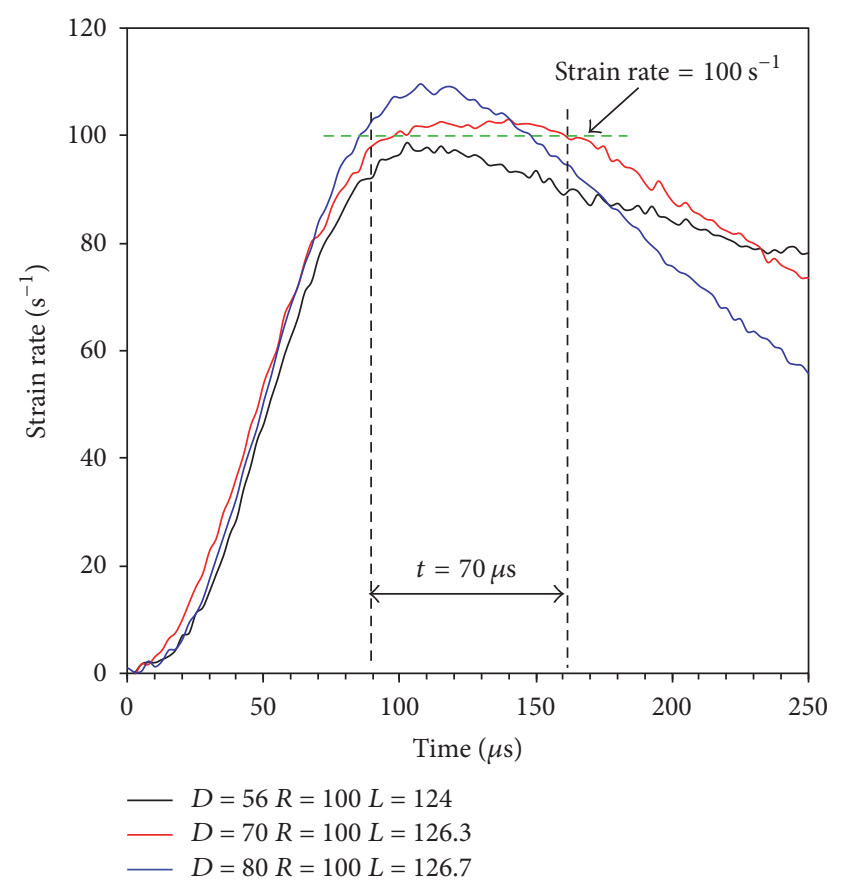

FIGURE 16: SHPB results for rock specimens with different hammers.

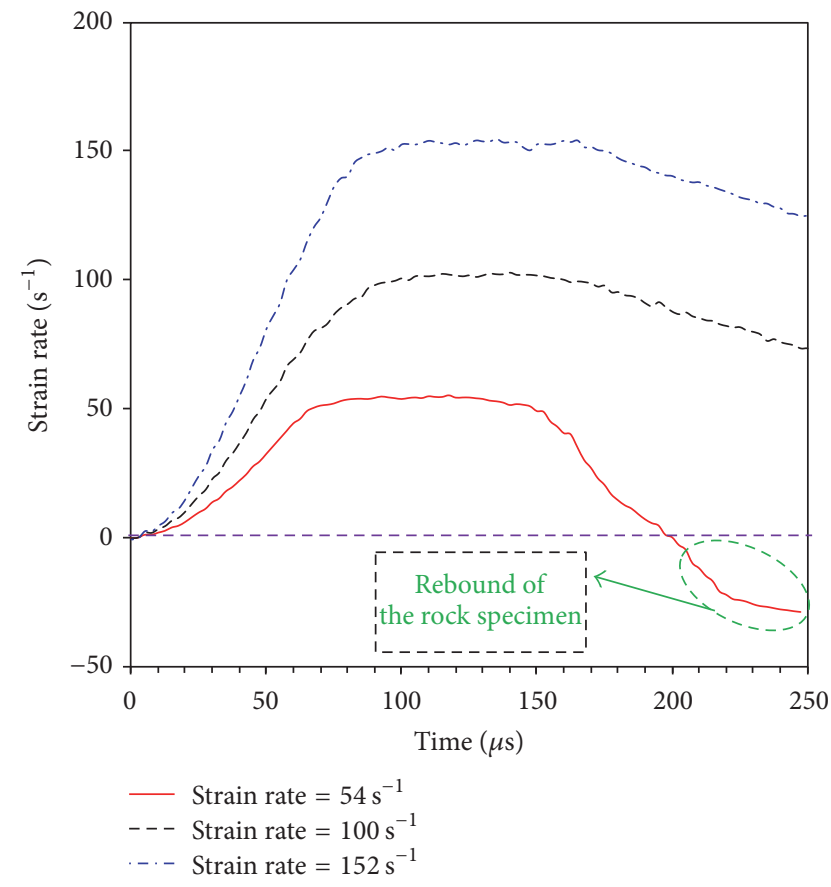

FIGURE 17: Strain rate histories of three green sandstone specimens.

4.2. Influence of Strain Rate on the Dynamic Property of Green Sandstone. Using the guidelines listed above, dynamic experiments of green sandstone were performed under strain rates of 54,100 , and $152 \mathrm{~s}^{-1}$, with the corresponding impact velocities of $2.5,3.0$, and $4.0 \mathrm{~m} / \mathrm{s}$, respectively.

Strain rate histories and stress-strain curves are shown in Figures 17 and 18, respectively. The stress-strain curves 


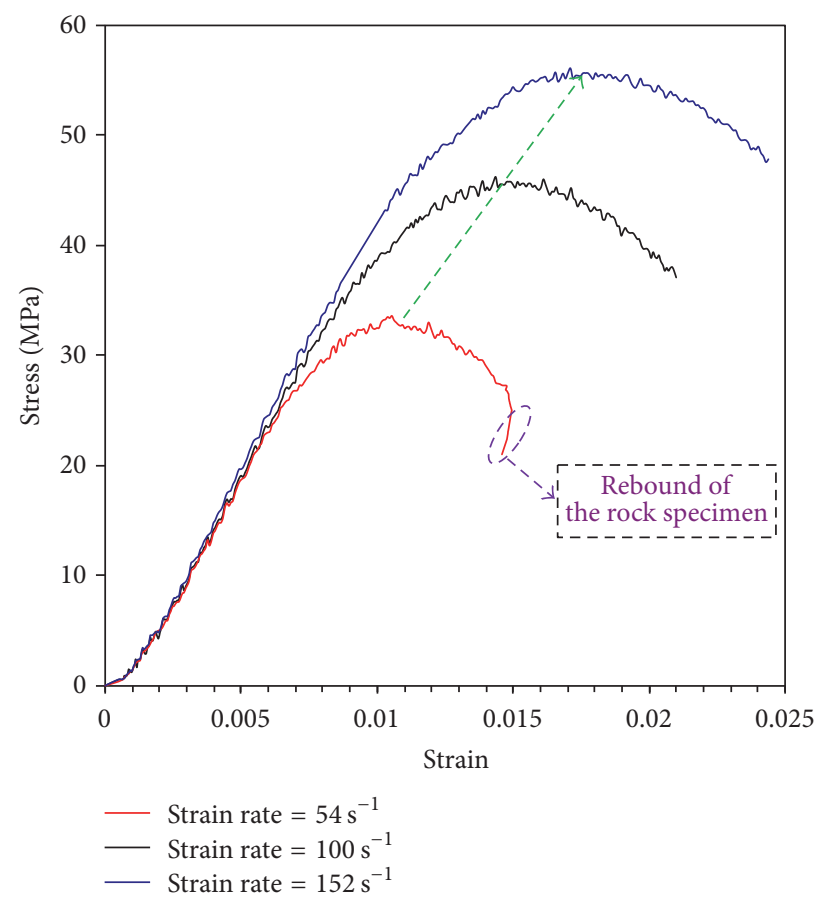

FIGURE 18: Stress-strain curves of green sandstone specimens.

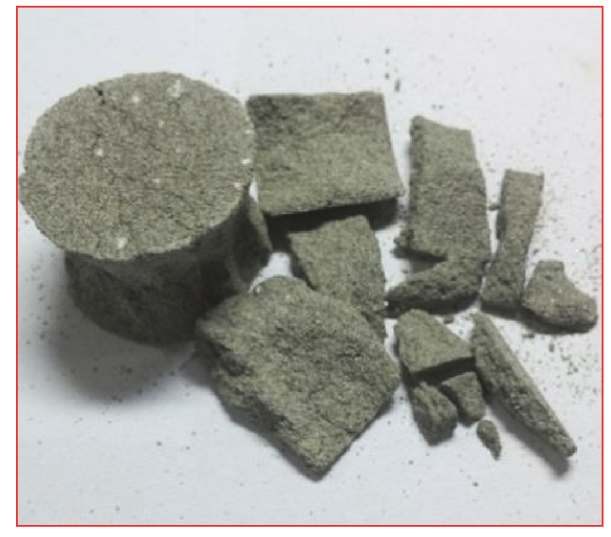

Strain rate $=54 \mathrm{~s}^{-1}$

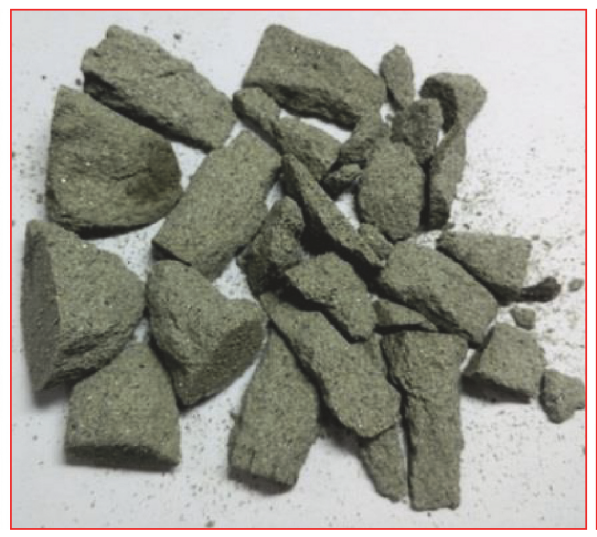

Strain rate $=100 \mathrm{~s}^{-1}$

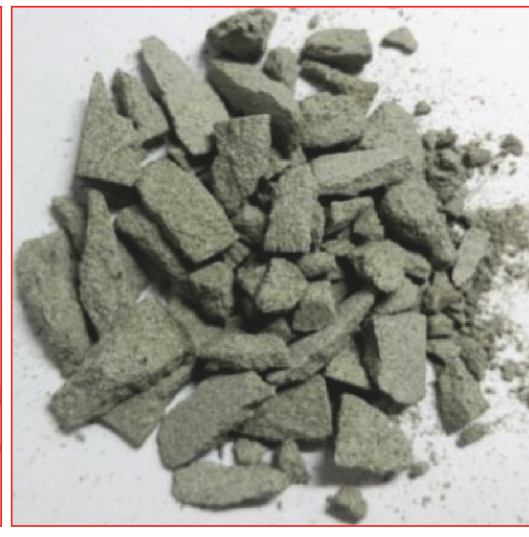

Strain rate $=152 \mathrm{~s}^{-1}$

FIGURE 19: Failure patterns of green sandstone specimens.

showed that the slope remained linear up to higher stress levels under dynamic impact, which indicated a delay in internal microcracking process. Furthermore, the initial tangent modulus was almost unaffected by strain rate, which was due to there being no significant internal microcracking during the initial loading stage [38]. In addition, with strain rates of 54,100 , and $152 \mathrm{~s}^{-1}$, the dynamic compressive strengths of the green sandstone were 33,43 , and $56 \mathrm{MPa}$, respectively, showing a rate-dependent effect. The critical strains (the strain corresponding to the maximum stress) were $0.01,0.014$, and 0.017 , respectively, which showed a rising trend with increased strain rate and meant that the green sandstone became more ductile at higher strain rates. In particular, owing to rebound of the rock specimen, the peak strain decreased with decreased stress under strain rate of $54 \mathrm{~s}^{-1}$.
The failure patterns of green sandstone specimens under strain rates of 54, 100, and $152 \mathrm{~s}^{-1}$ are shown in Figure 19. It is showed that the lateral strain was a main factor which led to spalling around the specimen edges at $54 \mathrm{~s}^{-1}$. Then, as the strain rate was increased from 54 to $100 \mathrm{~s}^{-1}$, the rock fractured into many pieces, including 5 wedge-shaped blocks. The rock sample fractured into small and pulverized pieces at $152 \mathrm{~s}^{-1}$. Thus, the dynamic fragmentation of the green sandstone showed an apparent rate-dependent property.

\section{Conclusions}

In this study, combining SHPB experiments with simulations, the effects of hammer geometric parameters and impact velocity on the shape of incident waves were studied. 
Simulations using a one-dimensional wave propagation program were validated by experimental results and could be utilized to predict the shape of incident waves generated by a hammer with a cambered surface at the impact site.

The loading rate of the incident wave linear segments, generated by the same hammer impact velocity, was affected mostly by hammer curvature radius. With the same curvature radius, the linear segment loading rate changed slightly with increased hammer diameter. Increased hammer impact velocity was found to have great influence on the linear segment loading rate. In SHPB experiments, an almost constant linear segment loading rate was achieved by keeping the curvature radius and impact velocity constant. Also, the shapes of the curved segment of incident waves were affected by hammer diameter as well as hammer length. With a larger diameter or a longer length, incident wave curvatures and curve stress peaks showed increasing trends, such that the general guidelines for selecting the proper hammer geometric parameters and impact velocity were presented. Thus, the trial and error process for selecting the proper hammer for SHPB tests was reduced.

Three hammers with different diameters were employed in SHPB tests to achieve a constant strain rate condition in green sandstone specimens. Because of the long duration of the linear portion of incident waves generated by three different hammers, dynamic stress equilibrium in specimens was perfectly fulfilled. Employing the guidelines for selecting the proper hammer, a constant strain rate condition that lasted for $70 \mu$ s was achieved with $8 \#$ hammer.

Dynamic experiments on green sandstone were carried out under strain rates of 54,100, and $152 \mathrm{~s}^{-1}$. The results showed that the initial tangent modulus was almost unaffected by strain rate, the strain of peak stress showed a rising trend with increased strain rate, and the dynamic fragmentation of green sandstone specimens exhibited a rate-dependent property.

\section{Conflicts of Interest}

The authors declare that they have no conflicts of interest.

\section{Acknowledgments}

This work is funded by the National Key Research and Development Program of China (Grant no. 2016YFC0801607), National Science Foundation of China (Grant nos. 51525402, 51374049, and 51574060), and the Fundamental Research Funds for the Central Universities of China (Grant nos. N160103005 and N150102002). These supports are gratefully acknowledged.

\section{References}

[1] K. P. Chong, P. M. Hoyt, J. W. Smith, and B. Y. Paulsen, "Effects of strain rate on oil shale fracturing," International Journal of Rock Mechanics \& Mining Science \& Geomechanics Abstracts, vol. 17, no. 1, pp. 35-43, 1980.

[2] D. E. Grady and M. E. Kipp, "Continuum modelling of explosive fracture in oil shale," International Journal of Rock Mechanics \&
Mining Sciences \& Geomechanics Abstracts, vol. 17, no. 3, pp. 147$157,1980$.

[3] H. Kolsky, "Stress waves in solids," Il Nuovo Cimento (19431954), vol. 1, no. 8, pp. 88-110, 1953.

[4] W. Chen and B. Song, Split Hopkinson (Kolsky) Bar, Springer, New York, NY, USA, 2011.

[5] K. Xia and W. Yao, "Dynamic rock tests using split Hopkinson (Kolsky) bar system - A review," Journal of Rock Mechanics and Geotechnical Engineering, vol. 7, no. 1, pp. 27-59, 2015.

[6] Z. Zhou, X. Li, Z. Ye, and K. Liu, "Obtaining constitutive relationship for rate-dependent rock in SHPB Tests," Rock Mechanics and Rock Engineering, vol. 43, no. 6, pp. 697-706, 2010.

[7] S. Ellwood, L. J. Griffiths, and D. J. Parry, "Materials testing at high constant strain rates," Journal of Physics E Scientific Instruments, vol. 15, no. 15, article 280, 1982.

[8] C. E. Frantz, P. S. Follansbee, and W. J. Wright, "New experimental techniques with the split Hopkinson pressure bar," in Proceedings of the Intern. conf. on High Energy Rate Fabrication, pp. 17-21, 1984.

[9] D. J. Parry, A. G. Walker, and P. R. Dixon, "Hopkinson bar pulse smoothing," Measurement Science \& Technology, vol. 6, no. 5, article 443, 1998.

[10] D. J. Frew, M. J. Forrestal, and W. Chen, "A split Hopkinson pressure bar technique to determine compressive stress-strain data for rock materials," Experimental Mechanics, vol. 41, no. 1, pp. 40-46, 2001.

[11] D. J. Frew, M. J. Forrestal, and W. Chen, "Pulse shaping techniques for testing brittle materials with a split Hopkinson pressure bar," Experimental Mechanics, vol. 42, no. 1, pp. 93-106, 2002.

[12] W. Chen, B. Song, D. J. Frew, and M. J. Forrestal, "Dynamic small strain measurements of a metal specimen with a split Hopkinson pressure bar," Experimental Mechanics, vol. 43, no. 1, pp. 20-23, 2003.

[13] D. J. Frew, M. J. Forrestal, and W. Chen, "Pulse shaping techniques for testing elastic-plastic materials with a split Hopkinson pressure bar," Experimental Mechanics, vol. 45, no. 2, pp. 186-195, 2005.

[14] K. S. Vecchio and F. Jiang, "Improved pulse shaping to achieve constant strain rate and stress equilibrium in split-Hopkinson pressure bar testing," Metallurgical and Materials Transactions $A$, vol. 38, no. 11, pp. 2655-2665, 2007.

[15] K. Xia, M. H. B. Nasseri, B. Mohanty, F. Lu, R. Chen, and S. N. Luo, "Effects of microstructures on dynamic compression of Barre granite," International Journal of Rock Mechanics \& Mining Sciences, vol. 45, no. 6, pp. 879-887, 2008.

[16] O. S. Lee, D. H. Kim, Y. H. Han, and Y. C. Park, "Dynamic deformation of hot temperature degraded POM and PP using a modified SHPB with pulse shaper technique," Journal of Mechanical Science and Technology, vol. 22, no. 9, pp. 1692-1698, 2008.

[17] W. Li and J. Xu, "Impact characterization of basalt fiber reinforced geopolymeric concrete using a 100-mm-diameter split Hopkinson pressure bar," Materials Science Engineering, vol. 513, pp. 145-153, 2009.

[18] R. Naghdabadi, M. J. Ashrafi, and J. Arghavani, "Experimental and numerical investigation of pulse-shaped split Hopkinson pressure bar test," Materials Science and Engineering: A Structural Materials: Properties, Microstructure and Processing, vol. 539, pp. 285-293, 2012. 
[19] X. Chen, S. Wu, and J. Zhou, "Experimental and modeling study of dynamic mechanical properties of cement paste, mortar and concrete," Construction and Building Materials, vol. 47, pp. 419430, 2013.

[20] W. F. Heard, B. E. Martin, X. Nie, T. Slawson, and P. K. Basu, "Annular pulse shaping technique for large-diameter kolsky bar experiments on concrete," Experimental Mechanics, vol. 54, no. 8, pp. 1343-1354, 2014.

[21] X. Chen, S. Wu, and J. Zhou, "Compressive strength of concrete cores under high strain rates," Journal of Performance of Constructed Facilities, vol. 29, no. 1, Article ID 06014005, 2015.

[22] X. Chen, L. Ge, J. Zhou, and S. Wu, "Experimental Study on Split Hopkinson Pressure Bar Pulse-Shaping Techniques for Concrete," Journal of Materials in Civil Engineering, vol. 28, no. 5, Article ID 04015196, 2016.

[23] A. Bagher Shemirani, R. Naghdabadi, and M. J. Ashrafi, "Experimental and numerical study on choosing proper pulse shapers for testing concrete specimens by split Hopkinson pressure bar apparatus," Construction and Building Materials, vol. 125, pp. 326-336, 2016.

[24] Z. Song, Z. Wang, H. Kim, and H. Ma, "Pulse shaper and dynamic compressive property investigation on ice using a large-sized modified split hopkinson pressure bar," Latin American Journal of Solids and Structures, vol. 13, no. 3, pp. 391-406, 2016.

[25] R. J. Christensen, S. R. Swanson, and W. S. Brown, "Splithopkinson-bar tests on rock under confining pressure," Experimental Mechanics, vol. 12, no. 11, pp. 508-513, 1972.

[26] X. B. Li, T. S. Lok, J. Zhao, and P. J. Zhao, "Oscillation elimination in the Hopkinson bar apparatus and resultant complete dynamic stress-strain curves for rocks," International Journal of Rock Mechanics and Mining Sciences, vol. 37, no. 7, pp. 10551060, 2000.

[27] T. S. Lok, X. B. Li, D. Liu, and P. J. Zhao, "Testing and response of large diameter brittle materials subjected to high strain rate," Journal of Materials in Civil Engineering, vol. 14, no. 3, pp. 262269,2002

[28] T. S. Lok and P. J. Zhao, "Impact response of steel fiber-reinforced concrete using a split hopkinson pressure bar," Journal of Materials in Civil Engineering, vol. 16, no. 1, pp. 54-59, 2004.

[29] X. B. Li, T. S. Lok, and J. Zhao, "Dynamic Characteristics of Granite Subjected to Intermediate Loading Rate," Rock Mechanics \& Rock Engineering, vol. 38, no. 1, pp. 21-39, 2005.

[30] X. Li, Z. Zhou, T. S. Lok, L. Hong, and T. Yin, "Innovative testing technique of rock subjected to coupled static and dynamic loads," International Journal of Rock Mechanics \& Mining Sciences, vol. 45, no. 5, pp. 739-748, 2008.

[31] X. Li, T. Zhou, and D. Li, "Dynamic strength and fracturing behavior of single-flawed prismatic marble specimens under impact loading with a split-hopkinson pressure bar," Rock Mechanics and Rock Engineering, vol. 50, no. 1, pp. 29-44, 2016.

[32] O. S. Lee and J. S. Park, "Dynamic deformation behavior of bovine femur using SHPB," Journal of Mechanical Science and Technology, vol. 25, no. 9, pp. 2211-2215, 2011.

[33] P. Baranowski, J. Malachowski, R. Gieleta, K. Damaziak, L. Mazurkiewicz, and D. Kolodziejczyk, "Numerical study for determination of pulse shaping design variables in SHPB apparatus," Bulletin of the Polish Academy of Sciences-Technical Sciences, vol. 61, no. 2, pp. 459-466, 2013.

[34] A. Bekker, T. J. Cloete, A. Chinsamy-Turan, G. N. Nurick, and S. Kok, "Constant strain rate compression of bovine cortical bone on the Split-Hopkinson Pressure Bar," Materials Science and Engineering C: Materials for Biological Applications, vol. 46, pp. 443-449, 2015.

[35] W. C. Zhu, L. L. Niu, S. H. Li, and Z. H. Xu, "Dynamic Brazilian test of rock under intermediate strain rate: pendulum hammerdriven shpb test and numerical simulation," Rock Mechanics and Rock Engineering, vol. 48, no. 5, pp. 1867-1881, 2015.

[36] Y. X. Zhou, K. Xia, X. B. Li et al., "Suggested methods for determining the dynamic strength parameters and Mode-I fracture toughness of rock materials," International Journal of Rock Mechanics and Mining Sciences, vol. 49, no. 1, pp. 105-112, 2012.

[37] D. X. Zou, "A nonlinear theoretical model of the partial deformation on longitudinally striken surface bars," Journal of Northeastern University (Natural Science), vol. 1, pp. 121-129, 1980.

[38] P. H. Bischoff and S. H. Perry, "Compressive behaviour of concrete at high strain rates," Materials and Structures, vol. 24, no. 6, pp. 425-450, 1991. 


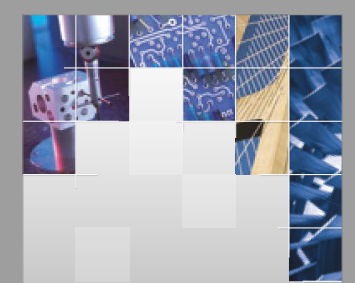

\section{Enfincering}
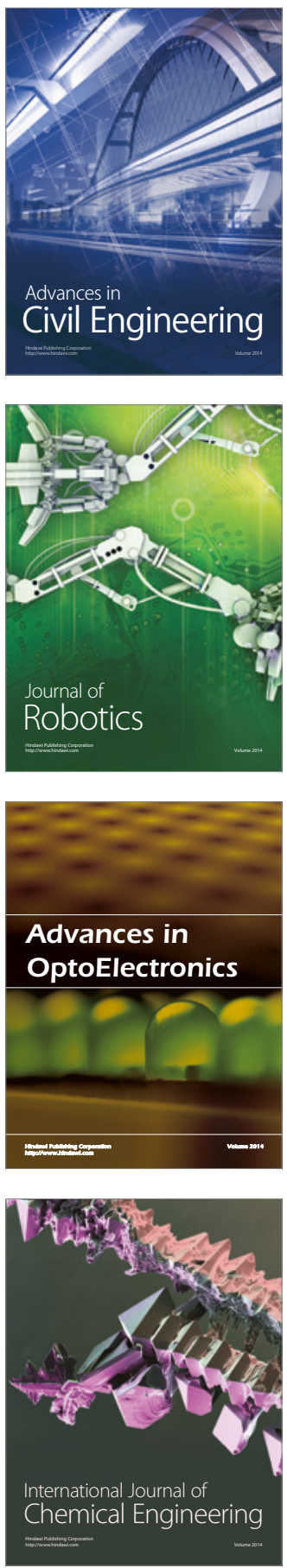

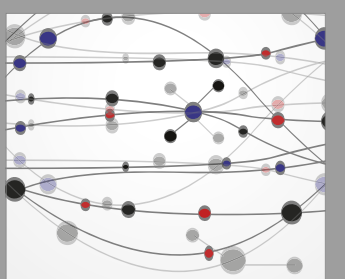

The Scientific World Journal

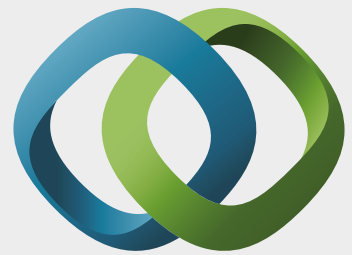

\section{Hindawi}

Submit your manuscripts at

https://www.hindawi.com
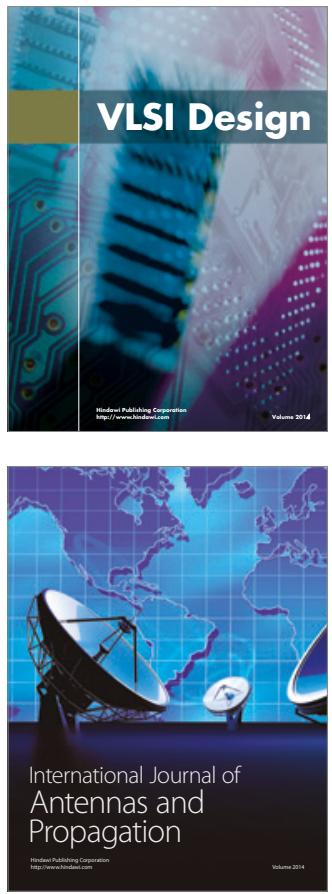

\section{Rotating}

Machinery
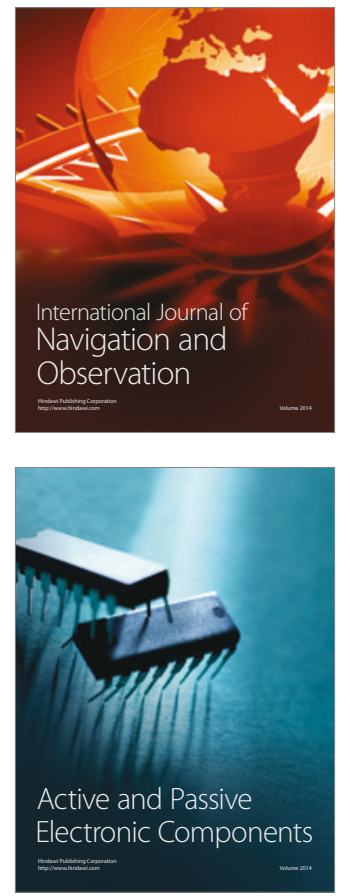
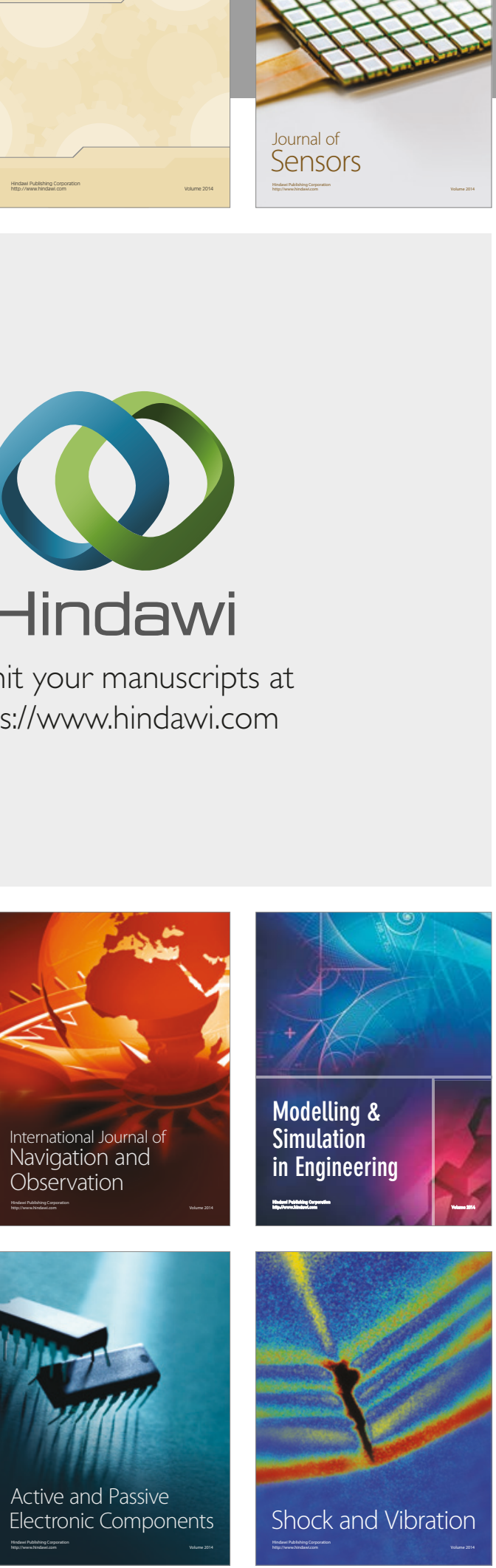
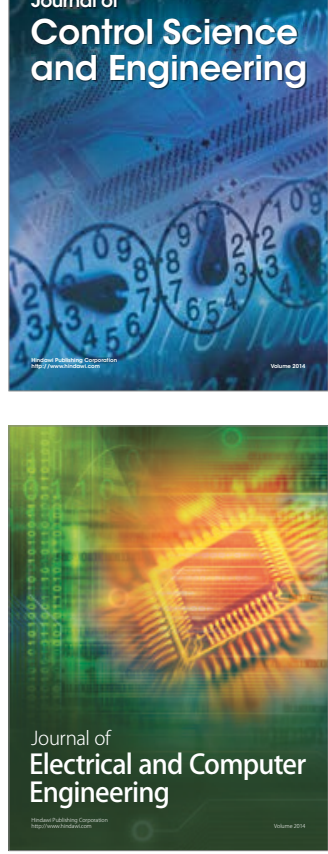

Distributed

Journal of

Control Science

and Engineering
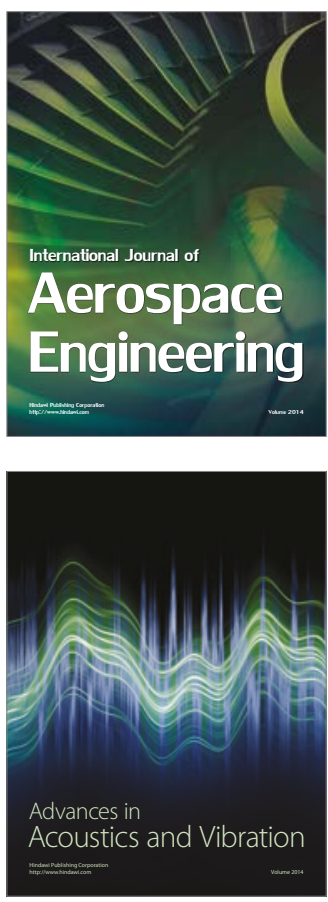

Sensor Networks 